\section{Liquide Bestattungskultur und Kirche}

\section{Kirchentheoretische Aspekte einer neuen Bestattungskultu}

David Plüss

\section{Einleitung}

Unsere Bestattungskultur ist im Wandel. ${ }^{1}$ Sie verändert sich derzeit rasant und unabsehbar. Möglicherweise wird dieser Wandel in ein paar Jahren im Rückblick als Paradigmenwechsel interpretiert. Wie er sich im Einzelnen zeigt, entfalten Corina Caduff und Matthias Grünewald in ihren Beiträgen in der vorliegenden Publikation. In diesem Beitrag geht es darum, zentrale Themen zu identifizieren und Probleme zu vertiefen, die Entwicklungen in historische Erzählzusammenhänge einzubetten und mögliche $\mathrm{Zu}$ kunftsszenarien zu erwägen. Ein solches Vorhaben ist anspruchsvoll, wenn und solange man sich mitten in der Stromschnelle befindet.

Wenn wir einen Schritt zurück gehen, um das gesamte Tableau zu überblicken, so ist eine solche Zusammenschau doch nur in groben Zügen möglich, mehr fragend als antwortend. Traugott Roser rückt in seinem Beitrag das Pfarramt und die Seelsorge ins Zentrum. Ich werde nach der Kirche fragen. Was bedeutet der aktuelle Wandel der Bestattungskultur für die Kirche? Wie verändert sie sich? Wie sind die Veränderungsprozesse im Einzelnen zu beschreiben und zu verstehen? Und wie reagieren Kirchgemeinden und Landeskirchen auf die faktischen oder sich abzeichnenden Veränderungen? Nach welchen Logiken und theologischen Grundsätzen erfolgen die kirchlichen Antworten und Strategien? Und wie sind sie zu

1 Für wertvolle Hinweise und Korrekturlektüren danke ich Dr. Katrin Kusmierz und Dr. Miriam Löhr.

Jahrbuch Diakonie Schweiz 4 (2020/2021) - ISSN 2504-3994

Dieser Text ist lizenziert unter einer Creative Commons Namensnennung 4.0 International Lizenz (CC BY 4.0): (https://creativecommons.org/licenses/by/4.0/)

beurteilen? Mit diesen Fragen ist der Horizont abgesteckt, in dem sich mein Beitrag bewegt. Selbstredend werde ich nur einzelne Aspekte erörtern können.

Ich bin überzeugt, dass es für Kirche und Theologie unabdingbar ist, gesellschaftliche «Megatrends» ${ }^{2}$ präzis ins Auge zu fassen, sie auszuloten und zu verstehen, um deren Chancen und Gefahren zu prüfen und eine angemessene Antwort zu finden. Dabei erweist sich eine theologisch motivierte und kirchlich orchestrierte Kulturkritik manchmal als notwendig und manchmal als sinnlos und naiv. Es gilt abzuwägen, wann Kritik und prophetischer Widerstand an der Zeit sind und wann nicht.

Was heisst das nun in Bezug auf Bestattung und Kirche? Isolde Karle hat 2004 im Deutschen Pfarrerblatt getitelt: «Volkskirche ist Kasualienund Pastorenkirche!» ${ }^{3}$ Der Titel endet mit einem Ausrufezeichen. Karle markiert ihn als starke These. Sie agiert wie eine Kampfsportlerin, die den Angriff der Gegnerin aufnimmt, um ihn in eine andere Richtung zu leiten. Der von innen und aussen an die Volkskirche gerichtete Vorwurf, mehr und mehr zu einer Dienstleistungskirche ohne Volk zu werden und dadurch zu verlottern, wendet sie um in eine starke These, mit der sie zum Ausdruck bringt: Just dies sind unsere Pfunde, mit denen wir zu wuchern haben, dies ist unser Tafelsilber. Und ich meine, sie hat recht. Die Volkskirche ist und bleibt Volkskirche als Kasualien- und Pfarrer:innenkirche. Bestattungen gehören zum Kerngeschäft unserer Kirchen. Auch distanzierte Mitglieder nehmen den Dienst gerne in Anspruch. Selbst Nichtmitglieder werden aus seelsorgerlichen Gründen kirchlich bestattet, zumal Bestattungen und Trauerfeiern im reformatorischen Verständnis keine

2 Zu den gesellschaftlichen Megatrends werden in der Religionssoziologie die Säkularisierung, die Pluralisierung und die Individualisierung gerechnet. Vgl. dazu Jörg Stolz / Judith Könemann u.a., Religion und Spiritualität in der Ich-Gesellschaft. Vier Gestalten des (Un-)Glaubens, Zürich 2014, 21-30

3 Isolde Karle, Volkskirche ist Kasual- und Pastorenkirche!, in: Deutsches Pfarrerblatt 12 (2004) 625-630.

Jahrbuch Diakonie Schweiz 4 (2020/2021) http://dx.doi.org/10.22018/JDS.2021.6 
Handlungen an der Leiche, sondern Gemeindefeiern sind, in denen das Leben der Verstorbenen im Licht der Verheissung vergegenwärtigt und den Trauernden Trost zugesprochen wird.

Das Pfarramt ist für die Bestattung, für die Kasualien überhaupt und für die Volkskirche zentral, nach wie vor. Vor bald 55 Jahren hat der Basler Praktische Theologe Walter Neidhart die Rolle des Pfarrers am Grab als die eines «Zeremonienmeisters» beschrieben und dadurch in einer von Karl Barth und seiner Theologie getränkten Kirche einen Sturm der Entrüstung entfacht. Neidhart fragt: «Was ist eine Beerdigung? Was ist konstant in dieser verwirrenden Fülle der Erscheinungen? In soziologischen Kategorien beschrieben, ist sie ein Gefüge von Bräuchen, mit welchen eine Gesellschaft das Sterben eines ihrer Glieder und die Beseitigung des Leichnams geregelt hat. Jede Kultur bildet für diesen Zweck ihre eigenen Bräuche aus. Ihnen allen gemeinsam ist die Konstanz des Zeremoniells, welche die Möglichkeit offen lässt, denselben Ritus (z.B. das Verbrennen von Wachs) verschieden zu deuten. [...] Damit ist die Frage nach der Rolle des Pfarrers im Beerdigungszeremoniell gestellt: Er ist zunächst «nolens volens〉 Funktionär des Brauchtums, und zwar amtiert er als ZZeremonienmeister〉. Dieser Begriff enthält nichts Abschätziges. Wenn wir einmal eingesehen haben, dass jeder Mensch auf die Hilfe der Gesellschaft und ihre Riten angewiesen ist, sträuben wir uns nicht dagegen, dass das Zeremoniell einen Leiter haben muss, der seinen Ablauf mit Befehlsworten, Gesten und Symbolen lenkt und es mit der Rezitation von traditionellen oder originalen, aber situationsgerechten Texten bereichert. Der Dienst des Zeremonienmeisters ist bei dieser Veranstaltung so wichtig wie der des Totengräbers oder des Wirtes, der das Beerdigungsmahl zubereitet.» ${ }^{4}$ - Neidharts Analyse war damals präzis und schlagend und ist es noch immer.

4 Vgl. Walter Neidhart, Die Rolle des Pfarrers beim Begräbnis (1968), in: Christoph Barben (Hg.), Aporien aushalten - dennoch handeln, Stuttgart / Berlin / Köln 1997, 210219 (213.215).
Bestattung, Pfarramt und (Volks-)Kirche gehören zusammen, sind aufeinander verwiesen, stärken oder schwächen sich. Das gilt auch dann, wenn alle drei Faktoren in einen Strudel der Veränderung gerissen werden, wie dies heute zumindest teilweise der Fall ist. Parallel zur Bestattungskultur wandeln sich auch das Pfarramt und die Kirche. In welcher Weise und in welche Richtung sich die Kirche verändert, werde ich im Folgenden erörtern. Ich gehe explorativ und exemplarisch zu Werke, indem ich zwei Fallbeispiele schildere und daraus mögliche Konsequenzen für die Kirche und das Pfarramt erwäge.

\section{Fallbeispiel 1: Der Dorfkönig hält posthum Hof}

Ich beginne mit dem ersten der von Matthias Grünewald vorgestellten Fallbeispiele: Eine Dorfgrösse stirbt - ein Mann mit Haus und Hofstatt und verhältnismässig grosser Nachkommenschaft. Von vier Söhnen ist die Rede. Es findet eine Trauerfeier in der Kirche statt, die nicht weiter beschrieben wird. Offenbar war die Feier unauffällig, wurde in der gewohnten Weise gefeiert, so, wie immer, beziehungsweise so, wie es sich für eine Dorfgrösse gehört: mit grosser Gemeinde, langem Lebenslauf und Dorfmusik, der der Verstorbene für einige Jahre als Präsident vorstand. Neben dem Pfarrer ergriffen auch ein Gemeinderat und die Präsidentin der Schulpflege, der der Verstorbene angehörte, das Wort. Sie fanden beide schöne, lobende Worte. Es folgte ein grosszügiges Leichenmahl im Landgasthof Bären mit ausreichend Chasselas, den der Verstorbene zu Lebzeiten seinen Gästen jeweils kredenzte. So weit, so gut und erwartbar. Aber nun kommt Bewegung in die Sache. Die Familie teilt dem Pfarrer die Bestattungswünsche des Verstorbenen mit: Seine Asche soll weder im anonymen Gemeinschaftsgrab noch in der modernen Urnenwand in Sichtbeton bestattet werden. Womöglich scheint ihm weder das namenlose Verschwinden noch die Gleichmacherei der modernen Urnenwand angemessen für die eigene Bestattung und sein Andenken. Die Asche soll vielmehr auf seinem Anwesen, in seiner grosszügigen und sorgfältig gepflegten Hofstatt um einen Apfelbaum eingestreut werden. Ich stelle mir vor, dass
Jahrbuch Diakonie Schweiz 4 (2020/2021) - ISSN 2504-3994 CC by 4.0
Jahrbuch Diakonie Schweiz 4 (2020/2021) http://dx.doi.org/10.22018/JDS.2021.6 
neben den Angehörigen Freunde und Bekannte eingeladen waren und erschienen sind - jedenfalls eine kleinere Gemeinde als in der Kirche -, um der eigenwilligen Bestattungsfeier beizuwohnen. Denn es wird ja nicht nur die Asche um den Apfelbaum eingestreut, sondern es werden auch die Zeugnisse des hochbegabten und schon vor einigen Jahren durch Suizid aus dem Leben geschiedenen Filius verbrannt.

Die Wünsche des Verstorbenen und seiner Familie fordern den Pfarrer heraus, der hier unübersehbar als Zeremonienmeister fungiert. Wie macht man das angemessen: Asche verstreuen?

Wir kennen das nicht. Es gibt bei uns dafür weder etablierte Rituale oder Anleitungen noch langjährige Erfahrungen. Und wie verbrennt man Prüfungsunterlagen in würdiger Weise? Was, wenn sie nicht recht brennen wollen oder die Asche hochsteigt und sich auf die Gemeinde verteilt? Soweit das erste Fallbeispiel. Ich habe es imaginativ angereichert, damit es Farbe und Konturen erhält.

Wie spiegelt sich die Kirche in diesem Beispiel? Offenbar war der verstorbene Dorfkönig Mitglied der Kirche. Das wird vorausgesetzt, scheint selbstverständlich. Die alteingesessene Dorfbevölkerung ist reformiert. Ebenso selbstverständlich findet die Trauerfeier in gewohntem Rahmen in der schönen Dorfkirche statt und wird vom Pfarrer geleitet. Womit die These von Isolde Karle belegt wird: Kirche ist hierzulande - zumindes im ländlichen Kontext - noch immer Kasualien- und Pfarrer:innenkirche. Und bei Trauerfeiern für dorfbekannte Persönlichkeiten mit grosser Gemeinde ist sie auch noch immer Volkskirche ${ }^{5}$. Lange Zeit war es üblich, dass jedes Haus zumindest eine Person für die Feier delegiert. Es gehörte sich so. Bekanntheit und Verbindlichkeit dieser Regel sind zwar weggebrochen, aber Alteingesessenen ist sie noch im Bewusstsein. Die in der Kirche und

5 Zu Begriff, Sache und theologischem Konzept der Volkskirche vgl. David Plüss / Matthias D. Wüthrich / Matthias Zeindler, Perspektiven einer Ekklesiologie der Volkskirche, in: dies. (Hg.), Ekklesiologie der Volkskirche. Theologische Zugänge in reformierter Perspektive, Zürich 2016, 395-438. zum Leichenmahl versammelte Gemeinde repräsentiert die Dorfgemeinschaft. An Trauerfeiern trifft man sich: die Einheimischen und die Weggezogenen. Erinnerungen werden aufgefrischt, durch den Lebenslauf in der Kirche und bei einem Glas Chasselas im Bären. Sind solche Trauerfeiern nicht noch immer so etwas wie sozialer Kitt, der die Dorfgemeinschaft zusammenhält, auch und gerade wenn diese immer vielfältiger wird und zu zerfleddern droht? Dem Pfarrer wird offenbar (immer noch) zugetraut, dass er die Trauerfeier schön und würdig gestaltet. Die Feier im Kirchenraum ist auch für jene erschwinglich oder unabdingbar, die sonst kaum je einen Gottesdienst besuchen.

Um die dramatischen Umbrüche der Bestattungskultur angemessen zu beschreiben und zu analysieren, ist es unabdingbar, das noch immer Stabile, Bewährte und Selbstverständliche dagegen zu halten. Sonst wird das Bild schief und falsch. Schub erfährt die Veränderungsdynamik in unserem Fallbeispiel durch den Wunsch des Verstorbenen nach einer Bestattung in der eigenen Hofstatt. Der Kirche und dem Pfarramt wird hier eine erstaunliche rituelle Flexibilität und Improvisationskunst abverlangt und zugetraut. Es wird dem Pfarrer zugemutet, dass er etablierte Rituale und Orte der Bestattung verlässt und sich auf neue und eigenwillige Ideen einlässt und diese liturgisch stimmig gestaltet. Liquid Church, die verflüssigte Kirche, ist eine Metapher, die der Praktische Theologe Pete Ward aus Durham (UK) zu einem Programm ausbaute und die von katholischer Seite breit rezipiert wurde, um sie gegen eine verkrustete und rechtlich armierte Kirchenstruktur ins Feld zu führen. ${ }^{6}$ Liquid Church zeigt sich in unserem Fallbeispiel nicht als Leitbild und Programm, sondern als gelebte Bestattungskultur. Kirchliche Rituale rund um die Bestattung sind einerseits noch immer fest und stabil, andererseits sind sie flüssig geworden und vielfältig, anpassungsfähig auch an eigenwillige Wünsche.

-

6 Vgl. Pete Ward, Liquid Curch, Peabody (Mass.) 2002; Michael Schüssler, Liquid Church als Ereignis-Ekklesiologie, in: PThI 34 (2014) 25-43; Pete Ward, Liquid Ecclesiology. The Gospel and The Church, Leden / Boston 2017.
Jahrbuch Diakonie Schweiz 4 (2020/2021) - ISSN 2504-3994

$$
\text { CC by } 4.0
$$

Jahrbuch Diakonie Schweiz 4 (2020/2021) http://dx.doi.org/10.22018/JDS.2021.6 
In diesem Fallbeispiel lässt sich eine Dialektik. feststellen zwischen festen und flüssigen Teilen und Elementen der Bestattungskultur, der Kirche und des Pfarramtes. Stabile, vertraute und erwartungssichere Rituale, Symbole, Worte und Räume sind womöglich unabdingbar dafür, dass kulturelle Veränderungsprozesse aufmerksam und mit Sympathie wahrgenommen und in hilfreicher und theologisch verantwortlicher Weise gestaltet werden können.

Ich greife einen zweiten Punkt auf: Das Priestertum der Glaubenden ist ein reformatorischer Grundsatz, der in die spätmoderne Gegenwart und zu den eigenwilligen Spiritualitäten unserer Kirch- und Zeitgenoss*innen passt. ${ }^{7}$ "Jede(r) ein Sonderfall?» lautet der etwas plakative Titel einer religionssoziologischen Studie, die vor 30 Jahren in der Schweiz durchgeführt wurde. ${ }^{8}$ Der Slogan könnte als pastorale Klage über Sonderwünsche und Extravaganzen in Sachen Bestattung oder als pointierte Übersetzung des reformatorischen Grundsatzes gelesen werden. Kann dem Wunsch des Verstorbenen, unter seinem Apfelbaum bestattet zu werden, nicht mi passenden biblischen Texten, theologisch gut unterfüttert und rituell sorgfältig gestaltet, nachgekommen werden? Solch rituelle Eigenwilligkeiten können als Zumutungen für das Pfarramt und Gefahr für die Identität der Kirche verstanden werden. Aber diese Lesart scheint mir einseitig. Der Wunsch lässt sich auch als Ausdruck des Priestertums aller Glaubenden und als Innovationsschub für die rituelle Praxis der Kirche deuten. Und könnte die etwas skurril anmutende Idee, die feierliche Verbrennung der Prüfungen des durch Suizid verstorbenen Filius mit der Baum-Bestattung zu verbinden, nicht produktiv gewendet, als Familienaufstellung verstanden, seelsorgerlich begleitet und als performative Bearbeitung eines über

7 Vgl. dazu David Plüss, Allgemeines Priestertum und Amt, in: Katrin Kusmierz u.a. (Hg.), Gottesdienst in der reformierten Kirche. Einführung und Perspektiven, Zürich 2017, 145-161.

8 Alfred Dubach / Roland J. Campiche, Jede(r) ein Sonderfall? Religion in der Schweiz, Zürich / Basel 1993.
Jahre schwelenden Familienkonflikts, der zwar bekannt war, an den der Pfarrer bisher aber nicht herankam, interpretiert und vollzogen werden?? Eine symbolische Darstellung und Bearbeitung, die der Kirche und dem Pfarramt offenbar zugetraut wird, obwohl damit die Grenzen des Bewährten weit überschritten werden?

\section{Fallbeispiel 2: Die maskierte Bestattung}

Anna Buchmüller ${ }^{10}$ stirbt im Dezember letzten Jahres mit 78 Jahren, ob am Corona-Virus, einer Mutation desselben oder an einem anderen Virus, wurde nicht abgeklärt. Jedenfalls setzte der Tod einer langen und belastenden Krankheitsgeschichte ein Ende. Anna Buchmüller litt seit vielen Jahren an einer Gefässerkrankung, welche sie zunehmend zermürbte und ihren Mann und ihre Töchter schwer belastete. Der Tod wurde von den Angehörigen insgesamt als Befreiung erfahren. Eine Feier in der Kirche war aufgrund staatlicher und kirchlicher Vorgaben nicht möglich. Die Bestattung fand im engsten Familienkreis im Freien auf dem winterkalten Friedhof statt, obwohl Anna trotz ihrer Erkrankung gut vernetzt war und bis zuletzt viele Kontakte pflegte. Alle Trauergäste mussten Masken tragen. Die Feier war kurz und spartanisch. Sang- und klanglos wurde die Urne bestattet. Die Tränen und Emotionen der Angehörigen waren hinter den Masken verborgen. Kein Händedruck, keine Umarmung, kein Leichenmahl und keine Gespräche im Sääli des Restaurants Bären bei belegten Broten und Chasselas. Die Einhaltung der Vorgaben wurde durch eine von der politischen Gemeinde bestellte Aufsicht überwacht. Diese Bestat-

9 Zur Familienaufstellung vgl. Bert Hellinger, Ordnungen der Liebe. Ein Kursbuch, Heidelberg 51998

10 Der Name ist frei erfunden, der Fall nicht.
Jahrbuch Diakonie Schweiz 4 (2020/2021) - ISSN 2504-3994

$$
\text { CC by } 4.0
$$

Jahrbuch Diakonie Schweiz 4 (2020/2021) http://dx.doi.org/10.22018/JDS.2021.6 
tung war für die Trauerfamilie unwürdig und verstörend. Die Überwachung auf dem Friedhof empfand sie als massive Störung einer würdigen Feier und als Eingriff in die persönliche Freiheit und Verantwortung.

Ich weiss, dass ich mit diesem Beispiel in einem Wespennest stochere. Ich verbinde damit einige Fragen, die auch und in besonderer Weise die Kirche betreffen. Mit der Pandemie geraten das Sterben und die Toten unvermittelt ins Licht medialer Aufmerksamkeit. Alle erinnern wir uns an die zur Hauptsendezeit über alle Fernsehkanäle vermittelten Bilder von Priestern in der Lombardei, die Covid-Erkrankten das Sterbe-Sakrament verabreichten und dabei das Risiko eingingen, selber zu erkranken. Viele erkrankten tatsächlich und starben. Die Frage, wie Sterben und Bestattung in Zeiten der Pandemie menschenwürdig gestaltet werden können, wird sogar in der säkularen Presse verhandelt. Kirche und Pfarrleute geraten in ein Dilemma. Die Gesundheit als hohes Gut und die Eindämmung der Ausbreitung des Virus stehen in krassem Widerspruch zur seelsorgerlichen Begleitung von Sterbenden, zu würdigem Abschiednehmen und Bestatten im Kreis all jener, die mit den Verstorbenen verbunden waren und sie von Herzen gerne auf der letzten Wegstrecke begleitet hätten. Während Bergbahnen weiterhin vollgepackt mit Sonnensüchtigen auf das Niederhorn über dem Thunersee oder die Schynige Platte bei Interlaken fahren, weil die Geschäftsführer*innen der Bergbahnen bei Politiker*innen offenbar gut lobbyiert haben, wurden im ersten und zu Beginn des zweiten Lockdowns würdige Formen des Abschiednehmens und der Bestattung kategorisch verunmöglicht. Wie werden wir und wie wird die Öffentlichkeit die Rolle und die Aufgabe der Kirche in der Pandemie in zwei oder fünf Jahren, wenn wir hoffentlich alles überstanden und eingedämmt haben werden, beurteilen? Waren die Kirchenleitungen, waren die Pfarrerinnen und Pfarrer mutlos oder war sie vernünftig? Beugten sie sich willfährig den staatlichen Vorgaben? Haben sie die Bedeutung der Begleitung von Sterbenden durch Lebensgefährten, Angehörige und Seelsorgerinnen ausreichend engagiert in die Waagschale geworfen? Haben sie die mediale Öffentlichkeit und die kommunalen Friedhofsverwaltungen hinreichend deutlich darauf aufmerksam gemacht, wie trostlos und verstörend eine sang- und klanglose Bestattung auf dem kalten Friedhof unter kommunaler Aufsicht auf die Angehörigen wirkt? ${ }^{11}$

Eine weitere Beobachtung vertieft die Fraglichkeit theologischen und kirchlichen Engagements in Zeiten der Pandemie: Warum ist eigentlich in der vielköpfigen Covid 19-Taskforce mit ihren zehn Expertengruppen zwar eine eindrücklich grosse Zahl an Fachexpert:innen und Berufsgruppen vertreten, aber keine Seelsorger:innen, keine Spiritual Care- oder Palliative Care-Expert:innen und keine Theolog:innen? Fehlt den Kirchen und der Theologie das Selbstbewusstsein in Bezug auf ihre Expertise in Sachen Ars moriendi? ${ }^{12}$ Die Wirtschaft ist jedenfalls deutlich besser aufgestellt als diejenigen, die tagtäglich mit Sterben und Tod befasst sind und sich auskennen in dem, was tröstet und Kraft gibt im Leben und im Sterben. ${ }^{13}$ Würde Kurt Marti heute wiederholen, was er zeitlebens angemahnt hat: dass die Kirche zu anpasserisch ist und rasch auf Linie geht, statt heikle Fragen zu stellen, Partei zu ergreifen und - ja - Widerstand zu leisten? ${ }^{14}$ Ich höre Stimmen vernünftiger und reflektierter Zeitgenoss:innen, die von der Kirche in dieser Krisenlage eine andere Haltung erwarten, eine kritischere, mutigere, offensivere.

Ich masse mir in der Sache kein abschliessendes Urteil an. Wir befinden uns in der Stromschwelle der Pandemie und keine:r weiss, wie die

11 Es handelt sich hier um konfligierende Werte: Gesundheit und Solidarität mit Risikogruppen zum einen und Sterbebegleitung, Bestattungskultur und Trauerbegleitung zum andern. Diese führen zu einem Dilemma und erfordern situatives Abwägen.

12 Ars moriendi ist die lateinische Bezeichnung für eine im Spätmittelalter entstandene Erbauungsliteratur, die zu einer Kunst oder Kultur des Sterbens anleiten will. Vgl. dazu Anne Klärner, Die Lebens-Kultur der ats moriendi. Literatur als Weg in der Lebensund Sterbebegleitung, Wuppertal 2006.

Damit bringe ich die erste Frage des Heidelberger Katechismus ins Spiel. Vgl. Georg Plasger / Matthias Freudenberg (Hg.), Reformierte Bekenntnisschriften. Eine Auswahl von den Anfängen bis zur Gegenwart, Göttingen 2005, 151-186.

14 Vgl. dazu exemplarisch: Kurt Marti, Red' und Antwort. Rechenschaft im Gespräch, Stuttgart 1988, 14-16. 
Sache ausgehen wird und wann wir wieder in ruhigeres Gewässer gelangen. Aber in Bezug auf Sterben, Tod und Bestattung stellen sich viele Fragen, die auch in der medialen Öffentlichkeit verhandelt werden. Zu diesen Fragen und Debatten haben sich Kirche und Theologie als Sachkundige in Bezug auf Sterben, Tod und Trauer zu Wort zu melden und sich einzubringen.

\section{Liquid Funeral, Liquid Church? - Fazit}

In welcher Weise und in welche Richtung verändern sich Pfarramt und Kirche durch die in Bewegung geratene Bestattungskultur? Ich schliesse mit einem Fazit in vier Punkten.

1) Es hat sich gezeigt: Die Metapher der Stromschnelle ist falsch oder zumindest einseitig. Die Bestattungskultur ist derzeit zwar im Wandel und mit ihr auch die Kirche und das Pfarramt. Aber dieser Wandel ist nur die eine, auffälligere, zuweilen grelle Seite. Im ersten Beispiel (und in vielen weiteren Fällen) gibt es daneben eine andere Seite: das Bewährte und Selbstverständliche der Bestattungskultur. Dazu gehören für viele die Kirchenmitgliedschaft, die Trauerfeier in der Kirche und die Bestattung durch die Ortspfarrerin. Das Bewährte fällt nicht auf und ist darum auch nicht der Rede wert. Aber es bildet so etwas wie das Fundament, auf dem - je nach Bedarf und Mode - moderne, eigenwillige oder naturreligiös-rituelle Aufbauten oder Annexe errichtet werden können.

2) Der Wandel der Bestattungskultur wird offenbar angetrieben durch eine forcierte Selbstbestimmung in Sachen Sterben und Tod. Ich hätte gerne noch ein Fallbeispiel mit assistiertem Suizid vorgestellt, um diesen Aspekt zu verdeutlichen. ${ }^{15}$ Das selbstbestimmte Sterben und die Planung der eigenen Bestattung sind nicht nur möglich geworden, sondern haben teilweise eine erstaunliche Selbstverständlichkeit erlangt. Hier sind Kirche und Pfarrer:innen herausgefordert: als Seelsorger:innen, Zeremonienmeister:innen und Trauerbegleiter:innen, welche die Wünsche der Betroffenen hören und ernstnehmen, theologisch reflektieren und verantwortlich gestalten. Das heisst nicht, dass jeder Wunsch erhört und tel quel umgesetzt werden muss. Das Ernstnehmen kann bedeuten, dass das Anliegen aufgenommen und gemeinsam eine angemessene Lösung gesucht wird. In einer Kirche, die das Priestertum aller Glaubenden betont und hochhält, hat ein solches Ernstnehmen einen guten theologischen Grund.

3) Die Bestattungskultur wird nicht nur von der Kirche und den Betroffenen bestimmt, sondern auch durch Friedhofsordnungen und staatliche Vorgaben. Dies wird in der Corona-Pandemie eindrücklich deutlich. Kirche und Pfarramt haben viel Erfahrung und Expert:innenwissen. Sie kennen hilfreiche Rituale und tröstliche Worte und Symbole im Umgang mit Sterben, Tod und Trauer. Sie sind Agenturen und Kompetenzzentren für die Ars moriendi. Dieses Wissen und diese Erfahrung gilt es selbstbewusster als bisher in die Waagschale zu werfen.

4) In der Corona-Pandemie fragt es sich, ob die Kirche und das Pfarramt nicht noch stärker als Fürsprecher der Sterbenden und der Angehörigen von

15 Vgl. dazu Christoph Morgenthaler / David Plüss / Matthias Zeindler, Assistierter Suizid und kirchliches Handeln. Fallbeispiele - Kommentare - Reflexionen, Zürich 2017; David Plüss / Christoph Morgenthaler, Trauerfeiern «on demand». Vom Umgang mit assistiertem Suizid, in: Thomas Klie (Hg.), On Demand. Kasualkultur der Gegenwart, Leipzig 2017, 135-152.
Jahrbuch Diakonie Schweiz 4 (2020/2021) - ISSN 2504-3994

$$
\text { CC by } 4.0
$$

Jahrbuch Diakonie Schweiz 4 (2020/2021) http://dx.doi.org/10.22018/JDS.2021.6 
Verstorbenen auftreten und sich in den öffentlichen Diskurs um würdige Formen des Sterbens und Abschiednehmens einbringen sollten, auch auf die Gefahr hin, missverstanden und in die falsche Ecke gestellt zu werden.

Autor:

David Plüss, Prof. Dr. theol., Professor für Homiletik, Liturgik, und Kirchen-

theorie an der Theologischen Fakultät der Universität Bern

$$
\text { CC by } 4.0
$$

